\title{
Sociology, biology and mechanisms in urban mental health
}

\author{
Nick Manning ${ }^{1}$
}

Published online: 5 December 2018

(C) The Author(s) 2018

\begin{abstract}
This paper examines the way in which sociology and biology continue to struggle to understand why urban life creates high levels of mental disorder. The movement of the world population to be majority urban in recent years adds urgency to this issue. The paper addresses ways in which sociological analysis and biological analysis might work together through the identification of mechanisms, imagined and confirmed through data, of the way in which urban life gets 'under the skin'. The argument moves from the use of mechanisms in scientific explanation, to the shortcomings of epidemiology, and the possibility of a new 'mechanism-rich' epidemiology. It then discusses seven examples of work that might contribute to this effort, concluding that more careful ethnography is required.
\end{abstract}

Keywords Sociology $\cdot$ Biology $\cdot$ Mechanisms $\cdot$ Urban $\cdot$ Mental $\cdot$ Health

\section{Introduction}

This paper examines the way in which sociology and biology continue to struggle to understand why urban life creates high levels of mental disorder. The movement of the world population to be majority urban in recent years adds urgency to this issue. The paper addresses ways in which sociological analysis and biological analysis might work together through the identification of mechanisms, imagined and confirmed through data, of the way in which urban life gets 'under the skin'. The argument moves from the use of mechanisms in scientific explanation, to the shortcomings of epidemiology, and the possibility of a new 'mechanism-rich' epidemiology.

Nick Manning

nick.manning@kcl.ac.uk

1 Department Global Health and Social Medicine, King's College London, Room BH NE 3.11, Aldwych, London WC2B 4BG, UK 
It then discusses seven examples of work that might contribute to this effort, concluding that more careful ethnography is required.

\section{The basic question}

The basic question concerns the relationship between urban life and mental disorder, and the issue is set out clearly by Van Os, who has been wrestling with it for more than 20 years:

Urban environment is one of the (proxy) environmental risk factors for psychotic disorder. ... Candidate mechanisms include higher level of perceived social isolation in urban areas and greater exposure to social "defeat" occasioned by higher level of competition in cities. (Frissen et al. 2017, p. 2).

This paper, following most research in this field, identifies urban life with social factors as opposed, for example, to air/noise/light pollution. This is almost universal in the literature, and we will follow this convention here. Despite many, many studies that have shown an association between mental disorder and urban life in general, and indeed between mental disorder and many specific aspects of urban life, it has been difficult to identify exactly how urban life 'gets under the skin'. In their review of the biology/sociology interface using urban mental health as the focus, Fitzgerald et al. (2016) suggest a new research strategy, to include thickly textured empirical research, shared sociological and neuropsychiatric attention, thicker ontology of urban mental health, and a redrawing of the urban (pp. 151-155). However, it is not immediately clear how to put this strategy into practice. One common and manifest problem is what counts as knowledge, argument, indeed good science in biology and sociology. Since this area of research self-evidently involves both biology and sociology, it follows that we need to work out how our question might be approached anew between and within these disciplines.

\section{Sociological and biological mechanisms}

One immediate issue is the question as to whether explanations developed in these two epistemic communities are compatible. How is research carried on? There are a myriad of research questions posed in each discipline, and data collected to throw light on them. Both disciplines use sophisticated statistical techniques, to identify patterns and associations, and both disciplines also use individual case studies as a way of digging into the processes through which particular things work. Each of these approaches is perceived to have reciprocal strengths and weaknesses. Associations do not explain why things 'go together'. Cases are not generalisable. Within each discipline, there have been strong disputes between these two types of research. Recently there has been a retreat in both disciplines from the high peaks of 'covering laws', but also from quantitative and qualitative rivalries, to the idea that explanation can be achieved through the identification of 'mechanisms' that connect one 
thing with another, but under limited circumstances. It is this development which gives us an opportunity and a strategy for re-examining our core question.

Mechanisms are a core part of explanation in biology, often accompanied by detailed graphical representation (Bechtel 2013a, b). Indeed, a critical debate about the general place of mechanisms in explanatory work has been centred on the case of the Nobel prize winning work of Hodgkin and Huxley (1952) on the way in which squid neurons fire signals from nerve cell to nerve cell via electrochemical mechanisms (Bogen 2008; Craver 2008; Schaffner 2008; Weber 2008; Levy 2014). Their series of papers in 1952 is intriguing because the mathematics worked, but with an incomplete mechanism, parts of which were wrong. However, the "diagram of the electrical circuit in a membrane and supplemented with details about how membranes and ion channels work, carry considerable explanatory weight. The equations without such interpretation ... do not constitute the explanation". (Craver 2008, p. 1028). Many other examples for biology are listed by Craver and Darden (2013), such as cellular transport, cell signalling, DNA repair, and mechanical articulation.

In sociology, the idea of mechanisms is more recent and, at least initially, used in rational actor models (Hedström and Swedberg 1998). However, a flourishing literature has challenged these early ideas to sketch out different varieties of mechanism explanation. Gerring (2008, p. 161) outlines nine different uses in social science, and Aviles and Reed (2017, p. 728) suggest that "mechanism warlordism' has emerged between mechanism fundamentalists (prone to reductionism under the guise of parsimony), and mechanism metaphorists, who prefer nuance and case studies, and see the social world as "dappled" (Cartwright 1999) where only some causes are best termed mechanisms. For sociology, the use of mechanism terminology is growing, with James Mahoney (2001) cataloguing 20 examples from well-known sociologists, reproduced by Margaret Archer in Generative Mechanisms Transforming the Social Order (2015). A recent example is the extensive use of mechanisms in Scambler and Scambler (2015) in their critique of theoretical faint-heartedness in much of the health inequalities literature-yet they offer neither reflection, nor definition of what they mean by the term 'mechanism'.

Bechtel and Richardson (1993) argue that decomposition and localisation were critical to the development of mechanistic models in the life sciences, drawing examples from cell biology, neuroscience, and genetics. Bunge (2004) similarly suggests that social science should examine social contexts; break things down into their composition, environment, and structure; identify relevant levels and exhibit their inter-relations; and look for mechanisms which enable growth or decay.

However, reductionism is neither ubiquitous nor necessary for mechanism construction; indeed Hodgkin and Huxley's work on the squid neuron "achieved unification and simplification in ... what might be termed "emergent simplifications" that transcend the specific workings of the molecular details". (Schaffner 2008, p. 1018). After all, mechanisms have to be imagined, and do not spring fully formed from the external world. As Mario Bunge comments "imagination both stimulated and constrained by data, well-weathered hypotheses ... is an art, not a technique" (2004, pp. 200-201). Recent work on these ideas has thus been to remove reductionism, stressing the way in which mechanisms might capture the emergent logic of biological and social processes, and to seek a core, simple and non-reductionist 
definition for a mechanism, for example, proposed by the philosopher Williamson (Illari and Williamson 2012): "A mechanism for a phenomenon consists of entities and activities organized in such a way that they are responsible for the phenomenon" (p. 132).

It is significant that this 'turn to mechanisms' in both biology and sociology offers a substantial methodological coherence between these disciplines at a time when both are themselves concerned to bring about a significant appreciation of the impact of each other's terrain on their core questions - for example, through epigenetics and neuroplasticity in biology, and through body and health research in sociology. How can this recent convergence help us in our quest to understand urban life and mental disorder? What might be the mechanisms? ${ }^{1}$

\section{Epidemiology, and its limits}

Perhaps the first port of call for identifying such mechanisms should be epidemiology, the traditional and still very active unpicking of quantitative associations of variables, drawn from both biological and social factors. Epidemiology is typically the collection of population-level data to identify risk and protective factors in relation to health or illness states, with increasingly small risks and increasingly specific factors identified through the use of very large samples. The development of 'big data' promises a new round and extension of this strategy.

The original epidemiological work on mental disorder and urban life was developed in the 1930s by Faris and Dunham (1939). Their Chicago data showed that schizophrenia was concentrated in the central city area, depression scattered across the city, with migrants and singletons having specific psychoses. Their hypotheses were that poor social relations lead to mental disorder, that 'downward drift' may make a contribution, and that there might be 'upward drift' of manic depression. In relation specifically to migrants, they suggested that 'adjustment difficulties' were linked to higher rates of mental disorder, that rates were higher for the mobile and heterogeneous, and that rates varied by race and by social class. These factors have continued to dominate epidemiological work, and indeed have been repeatedly rediscovered in later surveys. Density, ethnic mix and social class have re-appeared regularly, but with little sense that

\footnotetext{
1 Bhaskar's work is not referenced here since it is not really taken seriously, indeed rarely referenced, in the specialist literature on mechanisms (ie philosophy of science literature) for two reasons. One is that his later work really moved away from the clearer arguments of his early work. The second is that it is difficult to operationalise what he meant-hence none of the applied literature on mental health uses him much either. For example, Pawson (2016) comments that 'The fundamental difficulty is that Bhaskar was a philosopher, writing for philosophers about philosophy, with the consequence that he had little command of the conduct of empirical research (natural science or social science)' (pp. 49-50). Similarly, Bhaskar is not referenced at all in Jon Williamson's key paper "What is a mechanism? Thinking about mechanisms across the sciences" (Illari and Williamson 2012), nor his latest book (Parkkinen et al. 2018) Evaluating Evidence of Mechanisms in Medicine, Principles and Procedures.
} 
anything new has been said about why these factors are associated. Indeed for some authors, this has suggested an impoverished set of ideas:

We have a clear and strong signal telling us urban birth and urban residence increases the risk of developing schizophrenia. However, the quality of the data has not been matched by the quality of the hypotheses. ... Let's hope that the next decade of research on urbanicity and schizophrenia will be less ataxic and more focused. (Mcgrath and Scott 2006, p. 246)

Since this comment, the number of studies has certainly grown, but the identification of why and how there is an association between urban life and mental disorder remains elusive. A sample of recent epidemiological studies and reviews of factors associated with urban mental disorder includes the following list of familiar terms: This sample of papers could be multiplied many times over and extended to include genetic, environmental, psychological and historical factors. However, in them explanation rarely goes further than statistical association. There is almost no discussion of mechanisms to be found here, and the 'social' is actually measured in some very mundane ways, usually by employment, education, income, or social ties, with no real unpacking of what 'social' experience means in any detail.

An example is provided by some work arguably at the forefront of this kind of analysis (Schofield et al. 2016). This paper examines 'minority status and mental distress', using sophisticated statistical analysis. But the data are reduced to very imprecise categories, for example, 'occupational social class' is coded to a binary variable "advantaged (professional, managerial and technical, skilled non-manual and skilled manual) and disadvantaged (partly skilled, unskilled and unemployed) groups". (p. 3053). The data are subjected to sophisticated quantitative analysis, yet the authors themselves comment that

we were restricted to fairly crude definitions of minority status to achieve statistical power. Our definition of occupational social class was, by necessity, crude as we had to match classes at individual and area levels measured on different scales. Also comparison with the social class measure is hindered by the amount of missing data, 247 (15\%) missing responses, whereas this was negligible for the other measures. Our measure of single household status is also, by necessity, crude. For example, it could miss those who effectively live alone but are in shared households, due to economic necessity. (pp. 3055-56)

This combination of weak data with sophisticated numerical analysis is common in this literature. 


\section{Towards a new epidemiology?}

Criticisms have grown of the multiplication of increasingly sophisticated data handling and modelling, but without a concomitant growth in explanation of how typical risks and protections work in practice. A leading social epidemiologist, Sandro Galea, comments:

The body of work in the field that has explored how truly large-scale (macrolevel) forces shape the health of populations remains disproportionately limited..... A concern with the influence of urbanicity must, of necessity, involve samples that are heterogeneous across urban contexts and involve large samples that are collected across cities (Galea and Link 2013, p. 844)

He argues that epidemiology devotes too little attention to the mechanisms through which social factors enter the biological realm. He suggests the successful examples, smoking and papilloma virus, are rare, and that this is singularly not the case for urbanicity and mental disorder, which lacks a convincing elaboration of mechanisms.

(Galea and Link 2013) continues his argument through characterising epidemiology as a "black-box" discipline, focussing on factors that "may lead to the isolation of spurious associations or a chase for associations where there are none". His alternative is a "deeper grounding in a theory of the production of population health that stands on its own. With a few notable exceptions, epidemiology remains quite poor in this regard". (p. 847). More recently (in Keyes and Galea 2017), he has contrasted traditional epidemiology (seeking to identify whether exposure (e.g. urbanicity) is associated with disease), with what he terms 'causal architecture' (designed to identify the mechanisms that underlie disease).

In the same vein, the Harvard social epidemiologist Nancy Krieger (2011) has argued strongly for a move away from the dominant biomedical and lifestyle approaches in social epidemiology, which emphasise individual-level causes, towards an 'ecosocial theory' which includes the social, ecological and historical context. In short, epidemiology needs some social theory (Wemrell et al. 2016). Wemrell et al. suggest three areas in urgent need of theorisation: macro-social determinants of health and disease, categories of human difference, and embodiment.

\section{Mechanisms: in practice}

What work on urban life and mental disorder comes closer to Galea's causal architecture by seeking to identify mechanisms? We can review seven strategies.

\section{Strategy 1: Include everything: 'NEM III R'}

How can we link the huge scale differences between urban political economy and molecular biology that might be involved in urban mental health? The NEM III R (Network Episode Model) of the causes of mental disorder has been developed by 
sociologist Pescosolido over the last 25 years. Starting from a fairly simple model of patient networks, demographics and support systems (1991), she has extended it in NEM II to include the treatment system, and in NEM III to include the biological system (Pescosolido 2006, 2011; Perry and Pescosolido 2015).

This approach was developed explicitly to integrate the biological and social, through the specification of four basic requirements:

(1) "Consider and articulate the full set of contextual levels documented to have impact.

(2) Offer an underlying mechanism or 'engine of action' that connects levels.

(3) Employ a metaphor and analytic language familiar to both social and natural science.

(4) Understand the need for and use the full range of methodological tools". (Pescosolido 2006, p. 194).

The model broadly includes a time dimension covering an individual's life course, and a number of analytic levels, connected by networks, ranging across the biological, personal, social and system levels. In this sense, it is widely inclusive, but although the NEM model is strong in sensitising us to all the factors and levels which might be important, it is less clear about how to determine which mechanisms are the key ones. This is not just an empirical issue, as it is still not clear where to look. Pescosolido's answer is to follow the actors and their networks:

the entire process is dynamic, constituted, and embedded in individuals' social networks. What individuals know, how they evaluate the potential efficacy and suitability of a range of options and providers, and what they do (in what order and under which "tone") are fundamentally tied to, negotiated in, and given meaning through social interactions. (Pescosolido 2011, p. 45)

However, it should be noted that 'social interactions' is still biology-light. Actors here do not include the materialities of molecules, cells, membranes, and biological systems and structures. Despite her claim to the contrary, Pescosolido's approach is really quite thin on biology, and it occupies relatively little space in her work. She does not follow the actors 'all the way down' in the way so notable in actor network theory (Latour 2005, p. 52).

\section{Strategy 2: Cut through on a clear path: SES as a 'fundamental cause'}

NEM excels at bringing all possible factors to bear, but how do we find the network connections between levels that are active mechanisms? An alternative strategy is to cut a clear path through the myriad of possible factors with one major explanatory mechanism. This was proposed by Link and Phelan with the idea of 'fundamental cause'.

Urban life is a major multiplier of inequality: just as the world population has now become majority urban, inequalities grow all around the world (Amin 2007; Scambler and Scambler 2015). Urban life accumulates both the richest and the 
poorest. Even a cursory glance at the list of recent epidemiological studies of the social (Table 1) shows a common theme of disadvantage, deprivation, isolation, fragmentation, and discrimination. These are overlapping aspects of inequalities of income, status and power manifest in a variety of ways. Link and Phelan (1995) have suggested that (unequal) socio-economic status (SES) could be conceptualised as a fundamental cause (mechanism) of ill health (and of course by definition, good health). They do not suggest that SES stands in for a number of known and unknown specific mechanisms, but is in itself a dominant mechanism for understanding the experience of ill health (including of course mental ill heath). Even if specific diseases and therapies come and go, they argue that SES will continue to exercise dominance, as those with more resources gain disproportionate access to new healthcare and disproportionately avoid health risks. Resources, they predict, can

help individuals avoid diseases and their negative consequences through a variety of mechanisms. Thus, even if one effectively modifies intervening mechanisms or eradicates some diseases, an association between a fundamental cause and disease will re-emerge. As such, fundamental causes can defy efforts to eliminate their effects when attempts to do so focus solely on the mechanisms that happen to link them to disease in a particular situation. (Link and Phelan 1995, p. 81).

Over the subsequent 20 years, this prediction seems to have held up. Assessing the evidence that has accumulated in four areas, they suggest (Phelan et al. 2010) that SES does indeed shape disease outcomes via various risk factors, through the differential deployment of resources, a pattern which is very stable and reproduced over time via the emergence and decay of intervening mechanisms. This clearly leads in exactly the opposite direction from contemporary epidemiological sophisticationthere is little point in identifying more and more (and smaller) risk and protective

Table 1 Social epidemiologies of urban life

Socio-economic status, ethnicity, migration — and their intersection (Goodwin et al. 2017)

Social disadvantage, isolation and function (Morgan et al. 2017)

Socio-economic status and social inclusion (Yi and Liang (2017)

Social isolation and social "defeat" (Frissen et al. 2017)

Social minority status-ethnicity, household, social class (Schofield et al. 2016)

Social disadvantage (Stilo 2016)

Social status, social support, and racial discrimination (Mama et al. 2016)

Social networks, social support, and ethnicity (Smyth et al. 2015)

Social network structure and culture (Perry and Pescosolido 2015)

Social deprivation, social support, discrimination, stress, trust (Wickham et al. 2014)

Social coherence, density of social networks, and population density (Lederbogen et al. 2013)

Social adversity, population density, social fragmentation and deprivation (Heinz et al. 2013)

Social ties, social support, and stress buffering (Thoits 2011)

Socio-economic status, social capital, and social disorder (Kim 2008)

Social fragmentation, social isolation and social inequality (Van Os 2004) 
factors with larger and larger samples, if there is an underlying mechanism generated by SES that over time continues to reproduce ill health.

As originally defined and subsequently used, the term 'resources' is ambiguous. While Link and Phelan continue to emphasise resources, since wealth and money income will unequally confer potential and actual agency, it should be noted that other classical elements of SES, such as power, status, geographical clustering, and cultural habitus (including language) are likely parts of this mechanism, and indeed have been partially identified as such in a detailed ethnography exploring a fundamental cause analysis of diabetes in the USA (Lutfey and Freese 2005-discussed further below). In this respect, Link and Phelan's strategy is a case of "emergent simplification" mentioned at the beginning of this paper, where Schaffner (2008, p. 1018) discusses how to "transcend the specific workings of the molecular details".

\section{Strategy 3: Social psychology of small groups}

Another strategy has been to try to identify mediators between the social and the biological levels. Not as rigid as the 'fundamental cause' approach, these are the very small scale interactions that shape capacities and emotions. An example is research developed from the work of Henry Tajfel (1981) in the 1950s, aiming to understand stereotyping of Jewish people in WWII though the concept of 'everyday' or mundane categorisation, rather than the personal prejudices of the powerful. He focussed on the process of prejudice and stereotyping arising from the social judgements that people are typically hard wired to make in small groups. He showed that people's sense of identity is strongly influenced by the group in which they find themselves, and the way in which groups are categorised. There are similarities here to Goffman's (1986) work on stigma, and Scheff's (1974) work on labelling. In all three approaches, the individual both creates and receives categorical judgements about themselves and others in terms of the group context in which they find themselves (Phelan et al. 2008).

Indeed it is argued in this 'self-categorization theory' (Turner 1987) that there is a strong desire in people to ask 'who am I?' and to answer this through their perception of the groups they are in. While those making these judgments may strengthen their own identity in this way, the consequence for people who are so judged can be considerable. This may range from material exclusion (for example, from employment, housing), to 'social defeat' and shame-a particular experience for people with mental disorder, migrant status, and ethnic minority status (Reader et al. 2015). While much work in this area is based on animal studies, Reader et al. explore a number of ways in which the experience of social defeat 'gets under the skin' and into the brain via the hypothalamic-pituitary-adrenal (HPA) system. The link to urban mental health would be the way in which cities both destabilise the fixed social groups of rural life, and in addition multiply the opportunities, divisions and expectations for those who move to the city. 
Table 2 Diverse social capitals that affect mental health of young people

Family structure (e.g. number of parents present in the household)

Quality of parent-child relations (e.g. parent-child communication)

Adult interest in the child (e.g. parental involvement with school)

Parent's monitoring of the child (e.g. perceptions of parental monitoring/control)

Extended family support and exchange (e.g. perceptions of extended family support)

Social support networks (e.g. peer support)

Civic engagement in local institutions (e.g. volunteering)

Trust and safety (e.g. trust in others)

Religiosity (e.g. attendance at religious services)

Quality of the school (e.g. school cohesion and relationship between teachers and pupils)

Quality of neighbourhood (e.g. neighbourhood cohesion and social control) (McPherson et al. 2014)

\section{Strategy 4: Social capital}

The expanded conceptualisation of resources to include power, status, geographical clustering, and cultural habitus (including language), suggested by Lutfey and Freese (2005) above, is very close to another recent and increasingly common conceptualisation of 'the social'-social capital. While fundamental cause research resonates with the gloomy list of disadvantages and deprivations in Table 1, there is another rapidly growing literature on the mechanisms of social capital that might protect against mental disorder.

In a parallel development to the fundamental cause literature since the 1990s, social capital has come to embrace a bewildering variety of aspects of the social (Moore and Kawachi 2016). In a systematic review of the effects of social capital on mental health, De Silva et al. (2005) observe that social capital might include 'cognitive, structural, bridging, bonding, and linking' types, drawn from the very different theoretical traditions of Pierre Bourdieu, James Coleman and Robert Putnam. However, in the tradition of epidemiological evidence synthesis these are happily combined into a review as if they (more or less) extracted elements of a common underlying reality. Ten years later a further review (focussed on young people) illustrates the wide range of ideas that have been drawn under the idea of social capital (Table 2):

McPherson concludes not unreasonably that "It is, therefore, important that future research seeks to uncover the mechanisms through which social capital may exert different influences on the mental health" (p. 13).

\section{Strategy 5: Interaction ritual chains}

While Pescosolido emphasises what people know and what they $d o$, as the core aspects of social interactions, and Link and Phelan emphasise the deployment of resources, and social capital stresses the social context, there is further aspect of social life which hardly appears in these approaches. This is the point that there are 
important mental health consequence of the emotions generated by the way people live their lives in close and intimate proximity to one another. For example, stress is generated by high levels of negative emotional expression in families and, by contrast, trauma can result from low levels of emotional expression (e.g. neglect or isolation). There is evidence that both are bad for mental health (Koutra et al. 2014; Norman et al. 2012).

Sociological work on mechanisms that might analyse the effect of small/intimate groups such as families on emotions has been developed by Randall Collins and others on violence (2009) and 'interaction ritual chains' (2005) combining the traditions of Darwin, Durkheim and Goffman. Collins argues that we are biologically predisposed to emotional contagion in small group settings through physical and psychological rhythmic entrainment (resonance) which generates positive (or negative) emotional states, creating or releasing emotional stress (Fig. 1).

The biological roots of this mechanism he suggests are shared with non-human animals:

We have things of considerable importance to incorporate from Darwin and ethology. First and foremost is the proposition that society is subhuman. Many animals live in groups just as we do. The distinctively human forms of cognition and communication are built on top of the pre-existing capacity for social bonds; they are not the basis of it. (Collins 1975, p. 92, italics original)

Goffman, similarly, recognised that sociality is "located in a physical, biological, and social world" (Goffman 1974, p. 247). However, the biological pathways from bodies to rhythmic entrainment are not clear from Collins. One interesting possibility has been suggested by Heinskou and Liebst (2016), through the polyvagal parasympathetic part of the autonomic nervous system. This, they observe, is the neural pathway that regulates a number of internal organs, including the heart. It is phylogenetically the most recent subsystem and is connected to social communication, compared to the second oldest (fight-flight) and oldest (freezing or death feigning).

RITUAL INGREDIENTS

common
action or
event
(including stereotyped
formalities) $\rightarrow$
transient
emotional stimulus $\rightarrow$

common

action or

event

(including stereotyped formalities) $\rightarrow$

transient

emotional stimulus $\rightarrow$
RITUAL OUTCOMES

\begin{tabular}{c|c}
$\begin{array}{c}\text { group assembly } \\
\text { (bodily co-presence) }\end{array}$ \\
barriers to outsiders \\
$\begin{array}{c}\text { mutual focus of } \\
\downarrow \text { attention } \downarrow \\
\text { 个shared mood } \uparrow \\
\text { collective } \\
\text { effervescence } \\
\rightarrow \rightarrow \rightarrow \rightarrow\end{array}$ \\
$\begin{array}{c}\text { feedback } \\
\text { intensification through } \\
\text { rhythmic entrainment }\end{array}$
\end{tabular}

group solidarity

emotional energy

in individual

symbols of social

relationship

(sacred objects)

standards of

morality $\downarrow$

righteous anger for violations

Fig. 1 Interaction ritual chains (adapted from Collins 2005, p. 48) 
In short, they suggest that this mechanism might connect the Collins model with the polyvagal system, genuinely bringing the biological and social together.

\section{Strategy 6: Biology led mechanism}

Biological mechanisms have so far only been touched on. To move further in that direction, we can consider mechanisms that place biology more centrally. Pescosolido (2006, p. 194) suggested earlier that in seeking mechanisms it might be possible to "employ a metaphor and analytic language familiar to both social and natural science, so as to facilitate synergy'. Arroyo-Santos (2011) suggests that in biology 'the metaphor is a tool used to fulfill three major goals: 1) as an epistemic device seeking to provide a satisfactory explanation, 2) as an inferential device that can help infer new aspects of the phenomenon under investigation, 3) as an important theoryconstruction device'. (p. 89). It has already been noted from Bechtel (2013a, b) that the mechanisms that are a core part of explanation in biology are often accompanied by detailed graphical/metaphorical representation-indeed diagrams can be argued to be part of a full biological explanation. We should start therefore with a comment on metaphors and images in biology.

Biology has been particularly rich in the use of vivid metaphors and diagrams as a way of realising possible and actual mechanisms in various fields of its work. Hodgkin and Huxley represented their mechanism through a mathematical formula and electrical circuit used as a proxy mechanism for the squid neuron. The vagal nerve discussed earlier in relation to interaction ritual chains is frequently embedded in diagrams that link brain function to external stress, the HPA system and the gut microbiome. There are a number of common biological metaphors found in the literature, of which five are prominent. Table 3 suggests how they might be related to social and biological mechanisms.

The most common mechanism/metaphor to be found in the biology led literature on urban life is the proposal that external stressors (trauma, poverty, etc.) are invasive, or at least signal the need for biological changes. The use of this concept of stress is now almost universal. However, it has not always been so-indeed stress would be an excellent example of JS Mill's celebrated warning not "to believe that whatever received a name must be an entity or being, having an independent existence of its own" (Mill 1869, footnote 2). In a recent Wellcome project on the history of stress, Mark Jackson (2012, 2013, 2014, 2015) suggests that although the concept of stress was used in the late nineteenth century, it only became widely adopted after the second world war in the UK. Used initially to explain an upsurge in ulcers and other stomach disorders, it was taken up in psychiatry as war time migration and the newly established health and social services revealed the kind of lives that poorer people led.

The classic paper underpinning the modern era of stress research is McEwen and Stellar (1993), in which stress is described in the first paragraph as "physical stressors such as exertion, heat, cold, trauma, infection, and inflammation; psychologic stressors such as fear and anxiety, social defeat and humiliation, disappointment, and sometimes even intense joy" (p. 2093). Significantly, stress is not described in any 


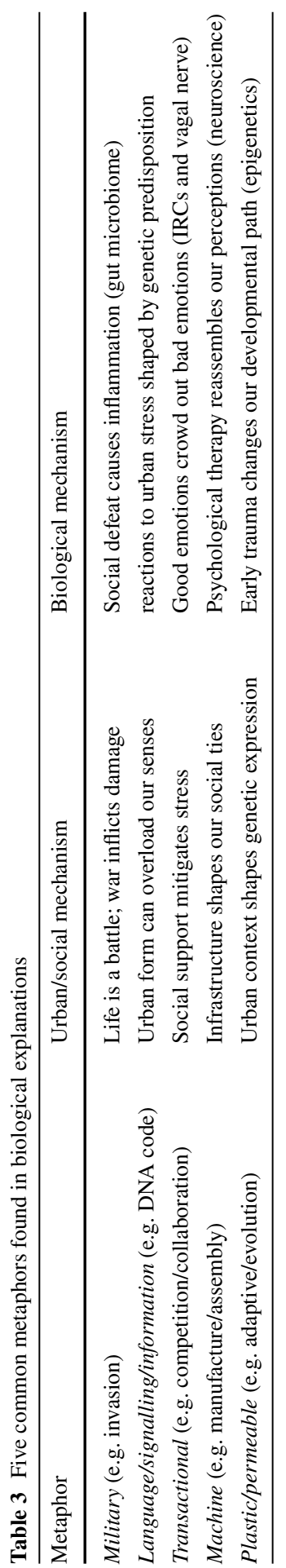




\section{Environmental stressors \\ Major life events $\downarrow$ \\ Trauma, abuse $\downarrow$ \\ (work, home, and neighbourhood) $\downarrow$}

Individual differences (genes,
development, and experience) $\rightarrow$

Allostasis $\rightarrow$

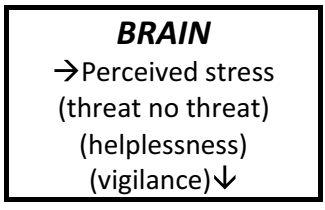

$\rightarrow$ Behavioural responses

(fight or flight)

(personal behaviour - diet,

$\leftarrow$ smoking, drinking, exercise)

$\rightarrow$ Physiologic $\leftarrow$ responses $\downarrow$

$\rightarrow$ Adaptation

\section{$\rightarrow$ Allostatic load}

Fig. 2 How the environment 'gets under the skin' (adapted from McEwen et al. 2015, p. T71)

further detail, but summarised as physical or psychological stimulus which threatens the individual. 'Allostatic load' is further defined as the accumulated 'wear and tear' of adjusting the natural balance (allostasis) such as heart rate, to threats over time.

However, Jackson's history raises the question, does stress really exist, and if so, what is it? The conceptualisation and measurement of stress, and its impact on allostatic load, is central. However, there is little clear idea of how this accumulation mechanism actually works, nor the units in which it might be measured. Allostatic load is now conventionally elaborated to include environment, life events, and early trauma, such that childhood trauma from many years earlier is added together with concurrent experiences, such as travelling though the city as measured by momentby-moment mobile technology, as illustrated by McEwan here (Fig. 2):

Three approaches have been used to elaborate the evidence for such stress mechanisms. One is to measure external social stressors and allostatic load in population surveys. Two comprehensive reviews suggest that this evidence has yet to be found. Dowd et al. (2009) conclude on the basis of the 26 studies they found that "Current empirical evidence linking SES [socio-economic status] to cortisol and AL (allostatic load) is weak. Future work should standardise approaches to measuring SES, chronic stress and cortisol to better understand these relationships". (p. 1297). (Cortisol level is the standard biomarker used to measure stress response). In a further recent review of studies since 2009, Johnson et al. (2017) state that "the scope of this review was limited to the biological internalization of SEP [socio-economic position] and the effects of this stressor on AL, highlighting AL as a mechanism on the causal pathway between SEP and health outcomes" (p. 1). The authors report that a total of the 59 different biomarkers were used in one or more of the 26 studies they found. The number of biomarkers used to create an AL index ranged between 6 and 25. There were 20 different biomarker combinations observed across the 26 studies included in the literature review. They conclude by observing how struck they were by the substantial inconsistency in biomarkers used to operationalise AL, and also by the lack of fidelity to its original conception as an index of biological response to 
stress. They argue it is difficult to know what is being measured by AL, or interpret findings about the association between SEP and AL.

The second approach is to induce stress in experimental events, as a proxy for the stress of 'urbanicity', and correlate this with experience of past or current urban living. A widely used approach is to subject experimental subjects to a situation of unfamiliarity and perceived social judgement, such as public speaking. This is associated with changes in cortisol levels in the blood, and seems robust. Using cortisol levels as a measure of stress in studies of mental disorder has become common-they are fairly easy to evaluate from saliva. However, the use of cortisol to measure stress raises a very real danger of circularity, in which stress is itself defined in terms of cortisol, since there is little reflection in the literature on whether public speaking is the 'same' stress as adverse life events, or childhood trauma, or urban living and whether those get 'under the skin' in the same way.

An example which has recently become widely influential is a study of how urban living and upbringing affect 'neural social stress processing' (Lederbogen et al. 2011). Two stress measures are used: the "Montreal Imaging Stress Task (MIST), a social stress paradigm where participants solve arithmetic tasks under time pressure" (p. 498) and a similar test in which "subjects performed two cognitive tasks (arithmetic and mental rotation) while being continuously visually exposed to disapproving investigator feedback through video" (p. 499). This is assumed to be a model of urban social stress, such that the authors conclude with the "parsimonious proposal that social stress contributes causally to the impact of urbanicity on the neural circuits identified" (p. 500). In a final flourish, they suggest that

Beyond mental illness, our data are of general interest in showing a link between cities and social stress sensitivity. This indicates that an experimental approach ... could be used to characterize further ... the effects of finergrained quantifiers of individuals' social networks or individual social experience in urban contexts. One such potential component is unstable hierarchical position. (p. 500, italics added).

These findings were not replicated in a subsequent study explicitly linked to the Lederbogen study, which used two different stress tests (Steinheuser et al. 2014). The Trier Social Stress Test asked subjects to "recall a list of 50 previously learned items in front of an audience" (p. 679). The Socially Evaluated Cold Pressor Test asked subjects to "immerse their right hand up to and including the wrist for $3 \mathrm{~min}$ (or until they could not tolerate it any more) into ice water". (p. 679).

It is a long extrapolation from such tests to an argument that the same stress is produced by an 'unstable hierarchical position', and it remains unclear how such psychosocial components create stress in the field, and how it is to be measured.

A third approach has been the development of a model of the 'the social brain' by Cacioppo in social neuroscience, looking at the consequences of social experience on the brain. The key area for his work has been the consequence of loneliness, i.e. the absence of the social, on brain function. Moreover, the key studies here have been with animals rather than humans, and the definition of the social is very limited. In a long review of 'Social Neuroscience: Progress and Implications 
for Mental Health', Cacioppo et al. (2007, p. 106), for example, define the social as 'social behaviour', which is classified into four subcategories of self-perception, self-regulation, interpersonal perception, and group processes. However, the fourth type, group processes, is dealt with in merely one sentence in this long and detailed review: "The stigma of physical and mental illness operates at the group or collective level of analysis" (p. 109). This is a substantial failure to grasp or work with the reality of human society, and a misleading use of the term social in 'social neuroscience' and the 'social brain'.

In relation to stress, this lopsided approach continues in a recent comprehensive review of stress and the 'social brain'. Sandi and Halle (2015) open as follows: "Stress (defined in this Review as the activation of the neurophysiological stress response) helps organisms to cope" (p. 290). Stress as a concept is thus collapsed into neurophysiological change, rather than separately theorised and measured. Stress becomes the neurophysiological response, rather than the social experience. Thus, the conceptualisation and measurement of stress arising from social life continues to prove elusive in practice. They comment that most of the studies they review are from animal studies (rodents), and thus stress is read off from small games and situations created for rodents to react to (p. 292). In common with the Lederbogen study (above), this is almost exclusively an animal-based review, which has equivocal findings, yet this has not inhibited the reviewers from concluding with an unsubstantiated and massive projection into human social life that

If stress that is caused by social disputes - such as war, physical abuse or aberrant socioeconomic inequalities - exacerbates antisocial dispositions in individuals, it may be instrumental in the development of spirals of violence (p. 300) (italics added)

\section{What is to be done?}

Mechanisms connecting urban life to mental disorder are both everywhere and elusive. Hundreds of papers are being produced looking at dozens of different variables, measured in different ways. Is there progress? And if so, what might this mean? How can we know more about urban life and mental disorder?

The key concept of stress is variable and unstable in its definition, and the social aspects of urban life are poorly articulated. While the proposal from Galea of a more theorised causal architecture is the right direction in which to move, this requires that the elements are clear; yet we see that in the literature to date too much of it either under- or miss-specifies both the nature of stress and the 'social'. The architecture, to continue that metaphor, requires a more careful scaffolding. Wimsatt (2014), for example, suggests three types of 'scaffolding' are necessary to underpin such concepts and their interrelations. He defines scaffolds as the "means through which other structures or competencies are constructed or acquired by individuals or organizations ... scaffolding for individuals, scaffolding for organizations, infrastructural scaffolding" (pp. 86-87). For example, individuals live their lives in a myriad of small face to face groups, such as families, friends, schools, associations, 
work teams, churches; they are also embedded in legal and administrative contexts, travel and distribution networks, and work organisations; underpinning all of which are infrastructures such as language, travel networks, information sources, shopping centres, networks for gas, water, power, telephone and waste removal. All of these are aspects of the social context within which stress is experienced. Yet very little of this kind of scaffolding appears in the papers reviewed so far, which could be applied not only to the lived experience of being in the city, but also the ways in which possible biological sub-systems work. As Krieger has put it more bluntly, "psychosocial analyses accord less attention, theoretically and empirically, to who and what generated psychosocial insults and buffers" (p. 198).

A key issue here is the idea that mechanisms are not merely aggregates of factors, or elements of scaffolds, but that they capture 'emergent' properties that are organised in very specific ways. Craver and Tabery (2017) distinguish between mechanistic (or organisational) emergence, whereby elements are arranged together in quite specific ways, and epistemic emergence, meaning that it is not possible to predict the properties of wholes from properties of the parts. In both cases, we need to seek out the relationship between urban lives, stress, and mental disorder in terms of mechanisms which are more than an aggregate of factors identified through statistical associations.

Given the under-specification of stress and the social, we suggest that detailed ethnography is now necessary to access urban experience which is associated with mental disorder, keeping an open mind as to what the lived experience of people might be. An example is Lutfey and Freese's (2005) ethnography of diabetes as an elaboration of the fundamental cause mechanism discussed earlier. In some ways, diabetes could be a proxy for mental disorder: it is a major cause of morbidity and mortality, with prevalence increasing dramatically; it is a long-term illness whose treatment depends heavily on patient self-management; it is related to SES; complications are known about. This simplifies the work of identifying potential mechanisms within an ethnographic inquiry (ibid, pp. 1332-1333). Their own model is (Fig. 3):

\begin{tabular}{lll}
$\begin{array}{l}\text { Central locus } \\
\text { of mechanism }\end{array}$ & $\begin{array}{l}\text { Attributed } \\
\text { location }\end{array}$ & $\begin{array}{l}\text { Perceived dispositional } \\
\text { Impediments }\end{array}$ \\
\hline
\end{tabular}

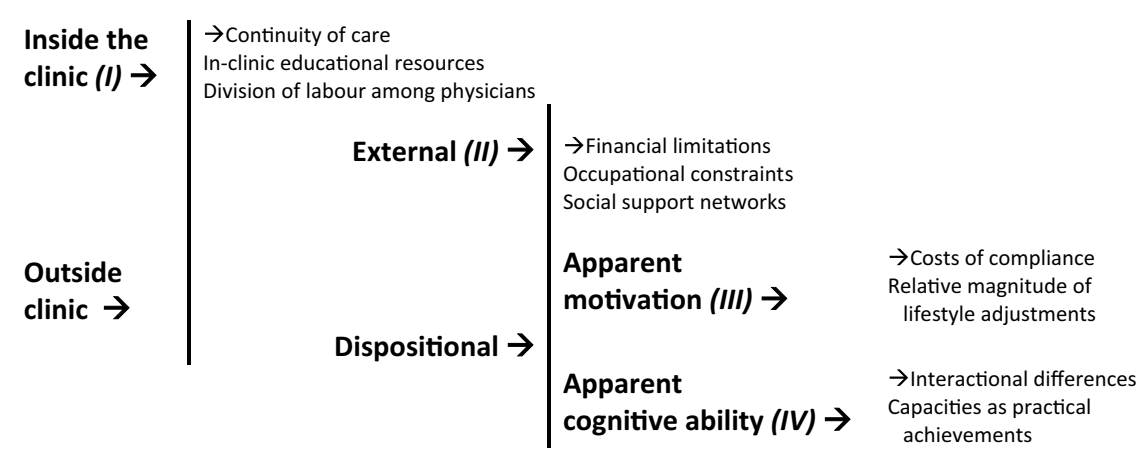

Fig. 3 An ethnography of diabetes mechanisms (adapted from Lutfey and Freese 2005, p. 1339) 
Their goal is to use ethnography to "articulate some of the mechanisms by which the inverse relationship between SES and health outcomes might be produced among persons with diabetes" (p. 1361).

Knowing that migration, ethnicity, poverty, density, pollution, noise and so on might be sources of urban stress, we have set up a major ESRC-funded ethnography of migrant workers in Shanghai to see what we might understand about the scaffolds surrounding their urban life and mental (di)stress. Our aim is to create a novel deepsurveying instrument for wider use on the (global) social epidemiology of urban mental health, and to inform strategies to address development priorities. Examples of such ethnography in support of innovative epidemiology can be found for hygiene (Larrea-Killinger et al. 2013), teen pregnancy (Béhague et al. 2008) and health seeking (Freidenberg et al. 1993).

\section{By way of a conclusion}

In an open letter to the actor Stephen Fry, who discussed frankly on television his own struggle for mental health, Richard Bentall (2016) wrote

a wide range of social and environmental factors increase the risk of mental ill health ...

poverty, urban environments, migration, ethnicity, early separation from parents, childhood sexual, physical and emotional abuse, bullying in schools, debt, unhappy marriages, demanding work, unemployment, to name but a few.

And he concluded that the "biggest cause of human misery is miserable relationships with other people, conducted in miserable circumstances".

But where does this leave us? It is far easier to question the factors, elements, mechanisms, associations etc. of others than to create something new. What is stress? Social capital? Socio-economic status? How do the microbiome, vagal nerves, and the HPA axis interact? What is and how does trauma work? Even if we understood these processes completely, what could we do? One way we might think about this is by turning in the other direction, away from the damages that urban life inflicts, towards an "urban utopianism based around four registers of solidarity woven around the collective basics of everyday urban life. These are 'repair', 'relatedness', 'rights' and 're-enchantment' (Amin 2006, p. 1009). Perhaps these could be the inspiration for new ways of thinking.

OpenAccess This article is distributed under the terms of the Creative Commons Attribution 4.0 International License (http://creativecommons.org/licenses/by/4.0/), which permits unrestricted use, distribution, and reproduction in any medium, provided you give appropriate credit to the original author(s) and the source, provide a link to the Creative Commons license, and indicate if changes were made. 


\section{References}

Amin, A. 2006. The good city. Urban Studies 43 (5-6): 1009-1023.

Amin, A. 2007. Re-thinking the urban social. City 11 (1): 100-114.

Archer, M. 2015. Generative mechanisms transforming the social order. New York: Springer.

Arroyo-Santos, A. 2011. The function of scientific metaphors: An example of the creative power of metaphors in biological theories. In The paths of creation: creativity in science and art, eds. S. Castro \& A. Marcos. Peter Lang, 81-96.

Aviles, N.B., and I.A. Reed. 2017. Ratio via machina: Three standards of mechanistic explanation in sociology. Sociological Methods \& Research 46 (4): 715-738.

Bechtel, W., and R. Richardson. 1993. Discovering complexity. Decomposition and localization as strategies in scientific research. Princeton: Princeton University Press.

Bechtel, W. 2013a. Understanding biological mechanisms: Using illustrations from circadian rhythm research. In The philosophy of biology, ed. K. Kampourakis, 487-510. New York: Springer.

Bechtel, W. 2013b. Addressing the vitalists' challenge to mechanistic science: Dynamic mechanistic explanation. In Vitalism and the scientific image in post-enlightenment science, 1800-2010, ed. S. Normandin and C.T. Wolfe, 345-370. New York: Springer.

Béhague, D.P., H. Gonçalves, and C.G. Victora. 2008. Anthropology and epidemiology: Learning epistemological lessons through a collaborative venture. Ciência \& Saúde Coletiva 13 (6): 1701-1710.

Bentall, R. 2016. All in the Brain?' an open letter to Stephen Fry, https://blogs.canterbury.ac.uk/discu rsive/all-in-the-brain/\#.VscA52Zud_U.twitter. Accessed 3 Nov 2017.

Bogen, J. 2008. The Hodgkin-Huxley equations and the concrete model: Comments on craver. Schaffner, and Weber' Philosophy of Science 75: 1034-1046.

Bunge, M. 2004. How does it work? The search for explanatory mechanisms. Philosophy of the Social Sciences 3, 4: pp 2004 182-210.

Cacioppo, J.T., et al. 2007. Social neuroscience: Progress and implications for mental health. Perspectives on Psychological Science 2 (2): 99-123.

Cartwright, Nancy. 1999. The dappled world: A study of the boundaries of science. Cambridge, UK: Cambridge University Press.

Collins, R. 1975. Conflict sociology: Toward an explanatory science. San Diego: Academic Press.

Collins, R. 2005. Interaction ritual chains. Princeton: Princeton University Press.

Collins, R. 2009. Violence: A micro-sociological theory. Princeton: Princeton University Press.

Craver, C. 2008. Physical law and mechanistic explanation in the Hodgkin and Huxley model of the action potential. Philosophy of Science 75: 1022-1033.

Craver, C., and L. Darden. 2013. Search of mechanisms: Discoveries across the life sciences. Chicago: University of Chicago Press.

Craver, C., and J. Tabery. 2017. Mechanisms in Science. In The Stanford encyclopedia of philosophy, ed. Edward N. Zalta. https://plato.stanford.edu/archives/spr2017/entries/science-mechanisms. Accessed 31 st Oct 2017.

De Silva, M.J., K. McKenzie, T. Harpham, and S.R.A. Huttly. 2005. Social capital and mental illness: A systematic review. Journal of Epidemiology and Community Health 59: 619-627. https://doi. org/10.1136/jech.2004.029678.

Dowd, J.B., A.M. Simanek, and A.E. Aiello. 2009. Socio-economic status, cortisol and allostatic load: A review of the literature. International Journal of Epidemiology 38: 1297-1309. https://doi. org/10.1093/ije/dyp277.

Faris, R.E.L., and H.W. Dunham. 1939. Mental disorders in urban areas: An ecological study of schizophrenia and other psychoses. Chicago: University of Chicago Press.

Fitzgerald, D., N. Rose, and I. Singh. 2016. Revitalizing sociology: Urban life and mental illness between history and the present. British Journal of Sociology 67 (1): 138-160.

Freidenberg, J., M. Mulvihill, and L. Caraballo. 1993. From ethnography to survey: Some methodological issues in research on health seeking in East Harlem. Human Organization 52 (2): 151-161.

Frissen, A., J. van Os, R. Lieverse, P. Habets, E. Gronenschild, M. Marcelis, et al. 2017. No evidence of association between childhood urban environment and cortical thinning in psychotic disorder. PLoS ONE 12 (1): e0166651.

Gerring, J. 2008. Review article: The mechanismic worldview: Thinking inside the box. British Journal of Political Science 38: 161-179. 
Goffman, E. 1974. Frame analysis: An essay on the organization of experience. Cambridge: Harvard University Press.

Goffman, E. 1986. Stigma: Notes on the management of spoiled identity. New York: Simon \& Schuster.

Galea, S., and B.G. Link. 2013. Six paths for the future of social epidemiology. American Journal of Epidemiology 178 (6): 843-849.

Goodwin, L., B. Gazard, L. Aschan, S. MacCrimmon, M. Hotop, and S.L. Hatch. 2017. Taking an intersectional approach to define latent classes of socioeconomic status, ethnicity and migration status for psychiatric epidemiological research. Epidemiology and Psychiatric Sciences. https://doi. org/10.1017/S2045796017000142.

Hedström, P., and R. Swedberg. 1998. Social mechanisms: An analytical approach to social theory. Cambridge: Cambridge University Press.

Heinskou, M.H., and L.S. Liebst. 2016. On the elementary neural forms of micro-interactional rituals: Integrating autonomic nervous system functioning into interaction ritual theory. Sociological Forum 31 (2): 354-376. https://doi.org/10.1111/socf.12248.

Heinz, A., L. Deserno, and U. Reininghaus. 2013. Urbanicity, social adversity and psychosis. World Psychiatry 12: 187-197.

Hodgkin, A.L., and A.F. Huxley. 1952. A quantitative description of membrane current and its application to conduction and excitation in nerve. The Journal of Physiology II7 (4): 500-544.

Illari, P.M., and J. Williamson. 2012. 'What is a mechanism? Thinking about mechanisms across the sciences. Euro Jnl Phil Sci 2: 119-135. https://doi.org/10.1007/s13194-011-0038-2.

Jackson, M. 2012. The pursuit of happiness: The social and scientific origins of Hans Selye's natural philosophy of life. History of the Human Sciences 25 (5): 13-29.

Jackson, M. 2013. The age of stress, science and the search for stability. Oxford: Oxford University Press.

Jackson, M. 2014. The stress of life: A modern complaint? Lancet 383: 300-301.

Jackson, M. 2015. (ed.) Stress in Postwar Britain, 1945-1980, Pickering and Chatto.

Johnson, S.C., F.L. Cavallaro, and D.A. Leon. 2017. A systematic review of allostatic load in relation to socioeconomic position: Poor fidelity and major inconsistencies in biomarkers employed. Social Science and Medicine. https://doi.org/10.1016/j.socscimed.2017.09.025.

Keyes, K.M., and S. Galea. 2017. The limits of risk factors revisited. Is it time for a causal architecture approach? Epidemiology 28 (1): 1-5. https://doi.org/10.1097/EDE.0000000000000578.

Kim, D. 2008. 'Blues from the neighborhood? Neighborhood characteristics and depression. Epidemiologic Reviews 30: 101-117. https://doi.org/10.1093/epirev/mxn009.

Koutra, K., A.N. Vgontzas, C. Lionis, and S. Triliva. 2014. Family functioning in first-episode psychosis: A systematic review of the literature. Social Psychiatry and Psychiatric Epidemiology 49 (7): 1023-1036.

Krieger, N. 2011. Epidemiology and the people's health, theory and context. Oxford: Oxford University Press.

Larrea-Killinger, C., R.F. Rego, A. Strina, and M.L. Barreto. 2013. Epidemiologists working together with anthropologists: Lessons from a study to evaluate the epidemiological impact of a city-wide sanitation program. Cadernos de Saúde Pública (Reports in Public Health) 29 (3): 461-474.

Latour, B. 2005. Reassembling the social. An introduction to actor-network-theory. Oxford: Oxford University Press.

Lederbogen, F., P. Kirsch, L. Haddad, F. Streit, H. Tost, P. Schuch, S. Wust, J.C. Pruessner, M. Rietschel, M. Deuschle, and A. Meyer-Lindenberg. 2011. City living and urban upbringing affect neural social stress processing in humans. Nature 474: 498-501. https://doi.org/10.1038/natur e10190.

Lederbogen, F., L. Haddad, and A. Meyer-Lindenberg. 2013. 'Urban social stress-risk factor for mental disorders. The case of schizophrenia' Environmental Pollution 183: 2-6.

Levy, A. 2014. What was Hodgkin and Huxley's achievement? The British Journal for the Philosophy of Science 65: 469-492.

Link, B.G., and J.C. Phelan. 1995. Social conditions as fundamental causes of disease. Journal of Health and Social Behavior 35: 80-94.

Lutfey, K., and J. Freese. 2005. Toward some fundamentals of fundamental causality: Socioeconomic status and health in the routine clinic visit for diabetes. American Journal of Sociology 110 (5): 1326-1372.

Mahoney, J. 2001. Beyond correlational analysis: Recent innovations in theory and method. Sociological Forum 16: 3. 
Mama, S.K., Y. Li, K. Basen-Engquist, R.E. Lee, D. Thompson, D.W. Wetter, et al. 2016. Psychosocial mechanisms linking the social environment to mental health in African Americans. PLoS ONE 11 (4): e0154035. https://doi.org/10.1371/journal.pone.0154035.

McEwen, B.S., and E. Stellar. 1993. Stress and the individual-Mechanisms leading to disease. Archives of Internal Medicine 153: 2093-2101.

McEwen, B.S., J.D. Gray, and C. Nasca. 2015. Redefining neuroendocrinology: stress, sex and cognitive and emotional regulation. Journal of Endocrinology 226 (2): T67-T83.

McGrath, J., and J. Scott. 2006. Urban birth and risk of schizophrenia: A worrying example of epidemiology where the data are stronger than the hypotheses. Epidemiologia e Psichiatria Sociale 15: 4 .

McPherson, K.E., S. Kerr, E. McGee, A. Morgan, F.M. Cheater, J. McLean, and J. Egan. 2014. The association between social capital and mental health and behavioural problems in children and adolescents: An integrative systematic review. BMC Psychology 2 (7): 1-16.

Mill, J.S. 1869. Footnote 2. In Analysis of the phenomena of the human mind, ed. James Mill, vol II, Longman 1829/1869, notes by JS Mill, chapter 14, p. 5.

Moore, S., and I. Kawachi. 2016. Twenty years of social capital and health research: A glossary. Journal of Epidemiology and Community Health 71: 513-517. https://doi.org/10.1136/jech-2016208313.

Morgan, C., et al. 2017. Ethnicity and long-term course and outcome of psychotic disorders in a UK sample: the ÆSOP-10 study. British Journal of Psychiatry. https://doi.org/10.1192/bjp. bp.116.193342.

Norman, R.E., M. Byambaa, R. De, A. Butchart, J. Scott, and T. Vos. 2012. The long-term health consequences of child physical abuse, emotional abuse, and neglect: A systematic review and meta-analysis. PLoS Medicine 9 (11): 1001349.

Parkkinen, V.-P., et al. 2018. Evaluating evidence of mechanisms in medicine, principles and procedures. New York: Springer.

Pawson, R. 2016. The ersatz realism of critical realism: A reply to Porter. Evaluation 22 (1): 49-57.

Pescosolido, B.A. 2006. Of pride and prejudice: The role of sociology and social networks in integrating the health sciences. Journal of Health and Social Behavior 47 (3): 189-208.

Pescosolido, B.A. 2011. Organizing the sociological landscape for the next decades of health and health care research: The network episode model iII-R as cartographic subfield guide. In Handbook of the sociology of health, illness, and healing, ed. B.A. Pescosolido, J.K. Martin, J.D. McLeod, and A. Rogers, 39-66. New York: Springer.

Perry, B.L., and B.A. Pescosolido. 2015. Social network activation: the role of health discussion partners in recovery from mental illness. Social Science and Medicine 125: 116-128.

Phelan, J.C., B.G. Link, and J.F. Dividio. 2008. Stigma and prejudice: One animal or two? Social Science and Medicine 67: 358-367.

Phelan, J.C., B.G. Link, and P. Tehranifar. 2010. Social conditions as fundamental causes of health inequalities: Theory, evidence, and policy implications. Journal of Health and Social Behavior 51 (S): $28-40$.

Reader, B.F., B.L. Jarrett, D.B. McKim, E.S. Wohleb, J.P. Godbout, and J.F. Sheridan. 2015. Peripheral and central effects of repeated social defeat stress: Monocyte trafficking. Microglial Activation, and Anxiety' Neuroscience 289: 429-442. https://doi.org/10.1016/j.neuroscien ce.2015.01.001.

Sandi, C., and J. Halle. 2015. Stress and the social brain: behavioural effects and neurobiological mechanisms. Nature Reviews Neuroscience 16: 290-304. https://doi.org/10.1038/nrn3918.

Scambler, G., and S. Scambler. 2015. Theorizing health inequalities: The untapped potential of dialectical critical realism. Social Theory \& Health 13, 3(4): 340-354.

Schaffner, K.F. 2008. Theories, models, and equations in biology: The heuristic search for emergent Simplifications in neurobiology. Philosophy of Science 75: 1008-1021.

Scheff, T.J. 1974. The labelling theory of mental illness. American Sociological Review 39 (3): 444-452.

Schofield, P., J. Das-Munshi, L. Bécares, C. Morgan, V. Bhavsar, M. Hotopf, and S.L. Hatch. 2016. Minority status and mental distress: A comparison of group density effects. Psychological Medicine 46: 3051-3059. https://doi.org/10.1017/S0033291716001835.

Smyth, N., C. Siriwardhana, M. Hotopf, and S.L. Hatch. 2015. Social networks, social support and psychiatric symptoms: social determinants and associations within a multicultural community 
population. Social Psychiatry and Psychiatric Epidemiology 50: 1111-1120. https://doi. org/10.1007/s00127-014-0943-8.

Steinheuser, V., K. Ackermann, P. Schonfeld, and L. Schwabe. 2014. Stress and the city: Impact of urban upbringing on the (re)activity of the hypothalamus-pituitary-adrenal axis. Psychosomatic Medicine 76: 678-685.

Stilo, S.A. 2016. Further evidence of a cumulative effect of social disadvantage on risk of psychosis. Psychological Medicine. https://doi.org/10.1017/S0033291716002993.

Tajfel, H. 1981. Human groups and social categories: Studies in social psychology. Cambridge: Cambridge University Press.

Thoits, P.A. 2011. Mechanisms linking social ties and support to physical and mental health. Journal of Health and Social Behavior 52 (2): 145-161.

Turner, J. 1987. Rediscovering the social group: A Self-categorization theory. Oxford: Blackwell.

Van Os, J. 2004. Does the urban environment cause psychosis? British Journal of Psychiatry 184: 287-288.

Weber, M. 2008. Causes without mechanisms: Experimental regularities, physical laws, and neuroscientific explanation. Philosophy of Science 75: 995-1007.

Wemrell, M., J. Merlo, S. Mulinari, and A.C. Hornborg. 2016. Contemporary epidemiology: A review of critical discussions within the discipline and a call for further dialogue with social theory. Sociology Compass 10 (2): 153-171.

Wickham, S., P. Taylor, M. Shevlin, and R.P. Bentall. 2014. The impact of social deprivation on paranoia, hallucinations, mania and depression: The role of discrimination social support, stress and trust. PLOS ONE 9 (8): e105140.

Wimsatt, W. 2014. Entrenchment and scaffolding: An architecture for a theory of cultural change. In Developing scaffolds in evolution, culture and cognition vienna series in theoretical biology, ed. L. Caporael, J. Griesemer, and W. Wimsatt, 77-106. Cambridge: MIT Press.

Yi, Y., and Y. Liang. 2017. The effect of socioeconomic status and social inclusion on the mental health of Chinese migrants: A comparison between interprovincial and intra-provincial migrants. Journal of Health Psychology. https://doi.org/10.1177/1359105317718058. 